\title{
Are invasive populations characterized by a broader diet than native populations?
}

\author{
Julien Courant ${ }^{\text {Corresp., }}{ }^{1}$, Solveig Vogt ${ }^{2,3}$, Raquel Marques ${ }^{4}$, John G Measey ${ }^{3}$, Jean Secondi ${ }^{5,6}{ }$, Rui Rebelo $^{4}$, \\ André De Villiers $^{3}$, Flora Ihlow ${ }^{2}$, Charlotte De Busschere ${ }^{7}$, Thierry Backeljau ${ }^{7,8}$, Dennis Rödder ${ }^{2}$, Anthony \\ Herrel ${ }^{9,10}$ \\ 1 \\ 1 UMR 7179, Département d'Ecologie et de Gestion de la Biodiversité, Centre national de la recherche scientifique, Paris, France \\ 2 Herpetology section, Zoologisches Forschungsmuseum Alexander Koenig, Bonn, Germany \\ 3 Centre of excellence for invasion biology, University of Stellenbosch, Stellenbosch, South Africa \\ 4 Centre for Ecology, Evolution and Environmental Changes, Faculdade de Ciências da Universidade de Lisboa, Lisboa, Portugal \\ 5 UMR CNRS 5023 LEHNA, University Lyon 1, Lyon, France \\ 6 UMR 6554 LETG - LEESA, Université d'Angers, Angers, France \\ 7 Royal Belgian Institute of Natural Sciences, Brussels, Belgium \\ 8 Evolutionary Ecology Group, University of Antwerp, Antwerp, Belgium \\ 9 Département d'Ecologie et de Gestion de la Biodiversité, Centre national de la recherche scientifique, Paris, France \\ 10 Evolutionary Morphology of Vertebrates, Ghent University, Gent, Belgium \\ Corresponding Author: Julien Courant \\ Email address: julien.courant@edu.mnhn.fr
}

\section{Background.}

Invasive species are among the most significant threats to biodiversity. The diet of invasive animal populations is a crucial factor that must be considered in the context of biological invasions. A broad dietary spectrum is a frequently cited characteristic of invasive species, allowing them to thrive in a wide range of environments. Therefore, empirical studies comparing diet in invasive and native populations are necessary to understand dietary requirements, dietary flexibility, and the associated impacts of invasive species.

\section{Methods.}

In this study, we compared the diet of populations of the African clawed frog, Xenopus laevis in its native range, with several areas where it has become invasive. Each prey category detected in stomach contents was assigned to an ecological category, allowing a comparison of the diversity of ecological traits among the prey items in the diet of native and introduced populations. The comparison of diets was also performed using evenness as a niche breadth index on all sampled populations, and electivity as a prey selection index for three out of the six sampled populations.

\section{Results.}

Our results showed that diet breadth could be either narrow or broad in invasive populations. According to diet and prey availability, zooplankton was strongly preferred in most cases. In lotic environments, zooplankton was replaced by benthic preys, such as ephemeropteran larvae.

\section{Discussion.}

The relative proportions of prey with different ecological traits, and dietary variability within and between 
areas of occurrence, suggest that $X$. laevis is a generalist predator in both native and invasive populations. Shifts in the realized trophic niche are observed, and appear related to resource availability. Xenopus laevis may strongly impact aquatic ecosystems because of its near complete aquatic lifestyle and its significant consumption of key taxa for the trophic relationships in ponds 


\section{Are invasive populations characterized by a broader diet than native populations?}

2 Julien Courant ${ }^{1}$, Solveig Vogt ${ }^{2,3}$, Raquel Marques ${ }^{4}$, John Measey ${ }^{3}$, Jean Secondi ${ }^{5,6}$, Rui Rebelo ${ }^{4}$, 3 André de Villiers ${ }^{3}$, Flora Ihlow ${ }^{2}$, Charlotte De Busschere ${ }^{7}$, Thierry Backeljau ${ }^{7,8}$, Dennis Rödder ${ }^{2}$ 4 and Anthony Herrel ${ }^{1,9}$

5 1. UMR 7179, Département d'Ecologie et de Gestion de la Biodiversité, Centre national de la recherche scientifique, 6 Paris, France.

7 2. Herpetology section, Zoologisches Forschungsmuseum Alexander Koenig, Bonn, Germany.

8 3. Centre of Excellence for Invasion Biology, University of Stellenbosch, Stellenbosch, South Africa.

9 4. Centre for Ecology, Evolution and Environmental Changes, Faculdade de Ciências da Universidade de Lisboa, 10 Lisboa, Portugal.

11 5. UMR CNRS 5023 LEHNA, University Lyon 1, Lyon, France.

12 6. UMR 6554 LETG - LEESA, Université d'Angers, Angers France.

13 7. Royal Belgian Institute of Natural Sciences, Brussels, Belgium.

14 8. Evolutionary Ecology Group, University of Antwerp, Antwerp, Belgium.

15 9. Evolutionary Morphology of Vertebrates, Ghent University, Gent, Belgium.

16 Short title: Diet of invasive and native populations.

17 Corresponding author: Julien Courant (jcourant@edu.mnhn.fr) 


\section{Abstract}

\section{Background.}

20 Invasive species are among the most significant threats to biodiversity. The diet of invasive

21 animal populations is a crucial factor that must be considered in the context of biological

22 invasions. A broad dietary spectrum is a frequently cited characteristic of invasive species,

23 allowing them to thrive in a wide range of environments. Therefore, empirical studies comparing

24 diet in invasive and native populations are necessary to understand dietary requirements, dietary

25 flexibility, and the associated impacts of invasive species.

\section{Methods.}

27 In this study, we compared the diet of populations of the African clawed frog, Xenopus laevis in

28 its native range, with several areas where it has become invasive. Each prey category detected in

29 stomach contents was assigned to an ecological category, allowing a comparison of the diversity

30 of ecological traits among the prey items in the diet of native and introduced populations. The

31 comparison of diets was also performed using evenness as a niche breadth index on all sampled

32 populations, and electivity as a prey selection index for three out of the six sampled populations.

\section{Results.}

34 Our results showed that diet breadth could be either narrow or broad in invasive populations.

35 According to diet and prey availability, zooplankton was strongly preferred in most cases. In

36 lotic environments, zooplankton was replaced by benthic preys, such as ephemeropteran larvae.

\section{Discussion.}


38 The relative proportions of prey with different ecological traits, and dietary variability within and

39 between areas of occurrence, suggest that $X$. laevis is a generalist predator in both native and

40 invasive populations. Shifts in the realized trophic niche are observed, and appear related to

41 resource availability. Xenopus laevis may strongly impact aquatic ecosystems because of its near

42 complete aquatic lifestyle and its significant consumption of key taxa for the trophic 43 relationships in ponds. 


\section{Introduction}

45 Invasive species usually occupy a wide geographical range in their native area. Invasive species

46 are typically characterized by a number of traits that favor the establishment and spread across

47 new ecosystems, including a broad environmental tolerances, high genetic variability, rapid

48 growth, early sexual maturity combined with a high reproductive rate, short generation time,

49 broad diet, gregariousness, rapid dispersal, and they are often commensal (Ricciardi and

50 Rasmussen, 1998). Of course not all invasive species meet all these criteria (Lodge, 1993). For

51 example, successful invaders do not necessarily exhibit a broad diet (Vazquez, 2006). Yet, a

52 large dietary niche breadth is frequently considered as a hallmark of an invasive taxon.

53 The dietary niche is a component of the Eltonian niche, defined as the position of an organism,

54 exhibiting a null population growth rate, in the trophic relationships with others organisms of the

55 ecosystem such as its nutrients, predators and competitors (Chase and Leibold, 2003). Another

56 aspect of the ecological niche is the Grinellian niche, defined as the set of all values of the

57 abiotic parameters enabling the occupancy of an area by a species (Soberón, 2007). The

58 Grinellian niche has known a recent intensification of research with the development of species

59 distribution models (e.g. Angetter, Lötters and Rödder, 2011; Guisan et al., 2013). Based on a set

60 of occurrence records and predictor variables, these models determine a given species

61 fundamental niche and facilitate the assessment of potential niche shifts when projected onto

62 novel conditions. While these models are based on the assumption that species retain their

63 ancestral traits over time (see Ackerly, 2003; Wiens and Graham, 2005) recent evidence

64 (Broennimann et al., 2007; Mukherjee et al., 2012; Stiels et al., 2015) revealing shifts in realized

65 Grinellian niches on a macro-ecological scale call this concept into question. How far Eltonian

66 niches operating on a population level are variable, under the assumption of niche conservatism, 
67 is less well studied. Whether a population maintains its characteristics, or shifts them in the

68 course of the invasion process will contribute determining its ecological impact. This

69 information is therefore of crucial importance for conservation practitioners facing the threat

70 posed by invasive species.

71 Native to southern Africa, the African clawed frog, Xenopus laevis, has been introduced in many

72 countries on four continents, where accidentally and deliberately released individuals have

73 established viable populations (see Measey et al., 2012). Despite its importance as model

74 biological organism (Cannatella and $\mathrm{De} \mathrm{Sa,1993),} \mathrm{and} \mathrm{the} \mathrm{abundance} \mathrm{of} \mathrm{invasive} \mathrm{populations,}$

75 few field studies have been undertaken in colonized ranges (for a review, see Measey et al.,

76 2012). Xenopus laevis has been reported to negatively affect the invaded ecosystems, and as a

77 consequence has been ranked as having the second greatest impact on native ecosystems by any

78 amphibian (Measey et al., 2016). Shifts in the Grinellian niche of $X$. laevis have been recently

79 demonstrated (Rödder et al., under review), whereas studies on changes in the Eltonian niches

80 have not yet been undertaken.

81 The diet of $X$. laevis has been studied in the species' native range of South-Africa (Schoonbee,

82 Prinsloo and Nxiweni, 1992), as well as in several introduced populations in the United States of

83 America (USA) (McCoid and Fritts, 1980), Wales (Measey, 1998a), Chile (Lobos and Measey,

84 2002), Italy (Faraone et al., 2008), Portugal (Amaral and Rebelo, 2012), and France (Courant et

85 al., 2014). In most studies, the majority of prey items are aquatic, with zooplankton and dipteran

86 larvae being the most frequent. Measey (1998b) also noticed the importance of terrestrial prey.

87 While stomach content analyses conducted in Portugal (Amaral and Rebelo, 2012) and in the

88 USA (McCoid and Fritts, 1980) revealed that $X$. laevis consumed eggs of fishes and amphibians,

89 no study has reported a direct impact linked to predation. A similar study, conducted in South 
90 African aquaculture ponds, revealed that farmed fish larvae constituted a large proportion (5 to

$9125 \%$ occurrence frequency according to fish size) of frog stomach contents (Schramm, 1987),

92 while another study found X. laevis to consume large quantities of anuran eggs and larvae (Vogt

93 et al., in press).

94 Given the wide diversity of prey items, dietary studies on $X$. laevis usually suggest a generalist

95 feeding behaviour, but only one study has thus far investigated prey electivity (Measey, 1998a).

96 No previous studies have explicitly compared the feeding behavior of populations in different

97 ecological contexts, and with different invasion histories. In this study, we compiled published

98 data on the diet of $X$. laevis from the USA (McCoid and Fritts, 1980), Wales (Measey, 1998a),

99 Chile (Lobos and Measey, 2002), and South Africa (Vogt et al., in press) with data collected

100 during recent field work in Portugal and France to test the hypotheses that (i) trophic niche

101 breadth is wider in native populations, hence releaving the capacity of the species to readily

102 adapt to novel environments; and (ii) the diet of invasive populations differs significantly

103 between the invaded ranges depending on local prey availability, and thus resulting in a low

104 degree of electivity and population-specific niche shifts. 


\section{Material \& Methods}

\section{Data sampling}

107 Our dataset comprised 1458 individuals from six countries, across four continents (Table 1). In

108 most areas (Chile, South Africa, Wales, France), frogs were caught using funnel traps. In

109 Portugal, animals were captured using electrofishing because the colonized habitats, mainly fast

110 flowing streams, prevented the use of traps. In South Africa, research permission was issued by

111 CapeNature (AAA007-01867) and SANParks, with ethics clearance from Stellenbosch

112 University Research Ethics Committee: Animal Care \& Use (SU-ACUD15-00011). Animals

113 from the Portuguese invasive population were captured under permit $n^{\circ}$ 570/2014/CAPT from

114 Instituto da Conservação da Natureza e das Florestas, in the scope of the "Plano de erradicação

115 de Xenopus laevis nas ribeiras do Concelho de Oeiras" (Erradication program of the council of

116 Oeiras for $X$. Laevis). In France, research permit was provided by the prefecture of the Deux-

117 Sèvres department.

118 Stomach content samples were obtained either by stomach flushing or dissection, following

119 euthanasia of individuals by lethal injection of sodium pentobarbital or immersion in MS222. We

120 considered that analyzing and comparing data collected with both dissection and flushing

121 methods were valid and did not induce any bias (Wu, Li and Wang, 2007).

\section{Data analysis}

123 Prey items retrieved from the stomach content samples were identified to the lowest taxonomic

124 level possible. However, for analytical consistency, we retained the lowest common taxonomic 125 level that could be identified for all prey items. As volume and mass of prey items were not 126 available for most studies, analyses were performed using prey frequencies. Each taxonomic 
127 prey category was assigned to one of the following ecological traits: plankton, benthos, nekton

128 and terrestrial. Some groups of invertebrates belong to different ecological trait categories

129 depending on their life stage, e.g. aquatic in their larval stage and terrestrial in their adult stage

130 (Diptera, Ephemeroptera, Trichoptera). Thus, adults and larvae were treated separately when

131 assigned to different ecological traits even though they belong to the same taxonomic prey

132 category.

133 The diet of populations was first compared by calculating the relative abundance of each prey

134 category and ecological trait. The relative abundance of prey classes (aquatic invertebrates,

135 terrestrial invertebrates, vertebrates) was also calculated. To assess variation in diet between

136 populations, a Principal Component Analysis (PCA) was performed on reduced and centered

137 relative abundances of each prey category.

138 The concept of niche breadth can be applied to comparative studies of diet between populations

139 or species (Slatyer, Hirst and Sexton, 2013), even if it has not always been treated within this

140 contextual vocabulary (e.g. Rehage, Barnett and Sih, 2005; Luiselli et al., 2007; Dalpadado and

141 Mowbray, 2013). We calculated niche breadth for all populations using the evenness measure $J$ '.

142 This index is based on the Shannon-Wiener's index $H^{\prime}$ (Shannon and Weaver, 1964), as

143 recommended by Colwell and Futuyma (1971):

144

$$
J^{\prime}=\frac{-\sum\left(\mathrm{p}_{\mathrm{i}} * \log \mathrm{p}_{\mathrm{i}}\right)}{\log n}
$$

145 Where $p_{i}$ is the proportion of the prey category $i$ in the diet and $n$ is the number of food 146 categories. 
147 To test whether $J$ 'is affected by the number of study sites the relationship of both variables was

148 assessed using a nonlinear regression.

149 Prey availability was quantified in habitats for three of the six populations (France, Wales and 150 South Africa) included in this study. Following Measey (1998a), the same sampling method was 151 applied to all populations. Prey selection was assessed using the Vanderploeg and Scavia's 152 (1979) relativized electivity index recommended by Lechowicz (1982):

$$
E^{*}=\frac{W_{i}-\frac{1}{n}}{W_{i}+\frac{1}{n}} \text { with } W_{i}=\frac{\frac{r_{i}}{p_{i}}}{\sum r_{i} / p_{i}}
$$

154 Where $r_{i}$ is the relative abundance of prey category $i$ in the diet and $p_{i}$ is the relative abundance

155 of prey category $i$ in the environment. The number of prey categories included in the analysis is 156 represented by $n$. 


\section{Results}

158 Across all samples zooplankton was the most common prey type with a mean relative abundance

159 of $56.21 \%$ (Standard Deviation $=32.80 \%$ ), followed by ephemeropteran larvae $(10.31 \% \pm$

$16023.40 \%)$, dipteran larvae $(9.68 \% \pm 7.23 \%)$, and gastropods $(7.24 \% \pm 6.07 \%)$. The fifth and sixth

161 most represented prey items were amphibian eggs, excluding $X$. laevis $(4.86 \% \pm 11.08 \%)$ and $X$.

162 laevis eggs $(3.46 \% \pm 7.55 \%)$ respectively. Three aquatic invertebrate orders (Coleoptera,

163 Diptera, and Hemiptera) were detected in all study sites (Table 2), while most of the terrestrial

164 categories were exclusively found in one or two sites. Cannibalism of larvae and/or eggs was

165 recorded in every locality, except Chile.

166 Aquatic invertebrates represented the most consumed prey item class, with a relative abundance

167 ranging from $66 \%$ in South Africa to $99 \%$ in Wales. Terrestrial invertebrates were rarely

168 consumed and consequently relative abundance ranged from $0.02 \%$ in France and the USA to

$1691.5 \%$ in Chile. Variability in relative abundance was highest for vertebrate prey, reaching a

170 maximal relative abundance of $33 \%$ in South Africa while being absent in Chile.

171 According to the PCA (Figure 1), the diet of the Portuguese and South African populations was

172 respectively characterized by high relative abundances of ephemeropteran larvae, and eggs of

173 native amphibians. The cluster representing Wales and Chile was characterized by a high

174 occurrence of zooplankton and a very low occurrence of all vertebrate prey items. Except for the

175 eggs of $X$. laevis, French and American samples share the three most abundant prey categories

176 (i.e. Diptera, Gastropoda, and Zooplankton), which explains the short distance between these

177 samples in the PC space. 
178 Benthic taxa represented $8.54 \%$ of the prey categories in South Africa, $6.87 \%$ in Wales, $14.85 \%$

179 in Chile, $28.8 \%$ in the USA, $55.87 \%$ in France, and $93.89 \%$ in Portugal (Figure 2). Nektonic taxa

180 represented $39.14 \%$ of the prey items in South Africa, $0.14 \%$ in Wales, $1.18 \%$ in Chile, $1.94 \%$ in

181 the USA, $4.20 \%$ in France, and $3.01 \%$ in Portugal.

182 Standardized evenness was 0.48 in South Africa, 0.10 in Wales, 0.27 in Chile, 0.42 in the USA,

1830.55 in France, 0.41 in Portugal (Figure 3a). The relationship between evenness $(J)$ and the

184 number of sampled sites $\left(N_{s}\right)$ followed a logarithmic function $\left(J^{\prime}=0.086 * \ln \left(N_{s}\right)+0.249\right.$; Figure

$1853 \mathrm{~b}$ ). The slope of the curve decreased from one to ten sites, and stabilized at 25 sites. There was

186 no correlation between trophic niche breadth estimations and the number of stomach contents

187 analyzed per population.

188 Negative electivity values were observed for most prey items (Figure 4). In contrast, zooplankton

189 was preferred (positive electivity) in the Welsh, South African and French populations. The

190 electivity values of the other prey categories were variable, indicating that they were either

191 selected, avoided, or not represented in the sampling. 


\section{Discussion}

193 In studies focusing on invasive species, both niche conservatism and niche shifts are commonly

194 reported in the literature (Tillberg et al., 2007; Caut, Angulo and Courchamp, 2008; Comte,

195 Cucherousset and Olden, 2016). Here, we report strong modifications in the realized dietary

196 niche between naturally occurring and introduced or invasive populations of $X$. laevis. While

197 these differences mainly constituted contractions or expansions of the realized dietary niche, the

198 diet of the Portuguese population represented a shift in the species' diet. Individuals from this

199 population were captured in fast flowing streams using electrofishing, while all others frogs were

200 caught in lentic environments. The difference might therefore be attributed to the habitat

201 characteristics, reinforcing the hypothesis that $X$. laevis is a generalist predator that modifies its

202 diet according to available resources.

203 Our study provides the first analysis of prey availability for a large number of sites that include

204 both natural and invaded areas. Our findings indicate that X. laevis may expand or shift some

205 dimensions of its trophic niche in novel environments. This result is significant, and has clear

206 consequences for evaluating conditions that favor the invasion of newly introduced populations.

207 Suitable trophic conditions allowing a positive population growth rate may be found in many

208 places where prey abundance is sufficient. A recent macroecological assessment revealed that

209 large areas of suitable climatic conditions were available outside the species' native range, and

210 that $X$. laevis was likely to expand its range in Europe as a result of climate change (Ihlow et al.,

211 2016). The broad global trophic niche of $X$. laevis and its ability to adapt its diet according to

212 local conditions, contribute to the strong invasive potential of this species, and the high impact it

213 may induce on its environment (see Measey et al., 2016). 
214 The diet of $X$. laevis has been studied in its native range (Schoonbee, Prinsloo and Nxiweni,

215 1992; Vogt et al., in press), and in different invasive populations (McCoid and Fritts, 1980;

216 Measey, 1998a; Lobos and Measey, 2002; Faraone et al., 2008; Amaral and Rebelo, 2012;

217 Courant et al., 2014). The first study carried out in the native range was performed in a fish farm

218 (Schoonbee, Prinsloo and Nxiweni, 1992), which does not necessarily represent the typical diet

219 of native populations. In most studies, including ours, X. laevis was found to predominantly

220 consume relatively small prey items. In Portugal, X. laevis mostly inhabits streams where

221 zooplankton is rare and the main prey items are benthic ephemeropteran larvae. Prey availability

222 in streams was not studied in Portugal, but collecting such data may help understanding the

223 dietary shift we observed in this population.

224 In all populations but Chile, predation on amphibians was observed, including $X$. laevis itself,

225 which represented the most frequent vertebrate taxon in the collective sample. This cannibalistic

226 behavior has been recorded in non-native populations, including in the USA (McCoid and Fritts,

227 1980), Wales (Measey, 1998a), Chile (Lobos and Jaksic, 2005), and Italy (Faraone et al., 2008)

228 but the high frequencies observed in France and South Africa are unprecedented. In the Chilean

229 population, autochthonous amphibians, as well as $X$. laevis eggs and larvae, were not observed

230 during the sampling period (JM, pers. com.) which may explain their absence in the diet. The

231 small number of stomach contents sampled and sites analyzed for this population may also

232 provide a biased assessment of the putative absence of native amphibians in this area. Predation

233 on amphibians was minor in most populations, except for the native range of $X$. laevis. This low

234 occurrence of predation on amphibians in other localities may be related to the season during

235 which studies were carried out, and possible changes in the behavior of native amphibians which

236 have co-existed with $X$. laevis for decades. Our study does not provide any evidence supporting 
237 this idea, but ongoing studies should bring new insights into this question. The noteworthy

238 anurophagy reported in this study corroborates the conclusions of Measey et al. (2015) regarding

239 the occurrence of this behavior among pipids.

240 In this study, terrestrial invertebrates represented the least consumed prey class. However,

241 cumulatively, there were as many taxonomic categories among terrestrial, as among aquatic

242 invertebrates. The occurrence of terrestrial prey items did not vary much between populations,

243 suggesting that there were no local specializations for the capture of terrestrial prey. In previous

244 dietary studies of $X$. laevis, authors concluded that the high portion of terrestrial prey could not

245 exclusively be explained by the capture of terrestrial invertebrates that had fallen into the water

246 (Measey, 1998b) but could represent captures occurring during terrestrial foraging during rainy

247 periods.

248 From a methodological perspective, sampling effort in each locality was heterogeneous with

249 respect to the sampling period, the number of prospected sites (range: 1-26), and the number of

250 individuals analyzed per population. Consequently, niche breadth could be under-estimated in

251 populations where only few sites were sampled (Wales, Chile, and USA) or where sites were

252 inter-connected (streams in Portugal). According to our results, there is a positive relationship

253 between diet breadth and the number of prospected sites. As no threshold was identified for an

254 optimal number of study sites, we would recommend using as many spatial and temporal

255 replicates as possible for studies aiming at comparing niche breadths. The diet of an individual

256 may be influenced by its size (Schafer et al., 2002), age (Gales, 1982; Rutz, Whittingham and

257 Newton, 2006), and sex independently of size (Gales, 1982; Göçmen et al., 2011, Van Ngo, Lee

258 and Ngo, 2014). In our study, these data were not available for every population, preventing us

259 from analyzing their effect on diet breadth. In other respects, the unique native population 
260 included in our study may not be representative of the diet in the native range. Estimations of

261 niche breadth and prey selectivity may have differed had they been based on a larger sample of

262 native populations. Therefore, we encourage future investigators to consider as many naturally

263 occurring populations as invasive populations in studies aimed at understanding the feeding

264 ecology of invasive animals.

265 Our results indicate that no prey categories are strongly selected, except for zooplankton in

266 Wales. This suggests that $X$. laevis does not usually specializes its diet and hence does not

267 develop a population specific dietary niche. This characteristic may enhance its capacity to

268 establish and spread in novel environments. Potential perturbations of $X$. laevis on its

269 environment, linked to the large predation on small prey items, are crucial elements of the

270 trophic relationships in aquatic ecosystems that still need to be demonstrated. Our results reflect

271 the diet of $X$. laevis in invasive populations after decades of colonization and do not necessarily

272 reflect the diet of the species at the moment of introduction. Some invasive species modify their

273 diet during the years, or decades following habitat colonization (e.g. Tillberg et al., 2007; Gkenas

274 et al., 2016). Comparing the diet of individuals at the core and the edge of a newly colonized

275 area may be an effective approach to investigate the change in dietary composition of $X$. laevis

276 during the colonization process. 


\section{Acknowledgements}

278 We are sincerely grateful to the two anonymous reviewers and the Academic Editor for their

279 helpful and constructive comments on the manuscript. 


\section{References}

282 Ackerly DD. 2003. Community assembly, niche conservatism, and adaptive evolution in 283 changing environments. International Journal of Plant Sciences 164:165-184.

284 Amaral P., Rebelo R. 2012. Diet of invasive clawed frog Xenopus laevis at Lage stream (Oeiras, 285 W Portugal). Herpetological Journal 22:187-190.

286 Angetter LS., Lötters S., Rödder D. 2011. Climate niche shift in invasive species: The case of the 287 brown anole. Biological Journal of the Linnean Society 104:943-954. DOI: 10.1111/j.1095288 8312.2011.01780.x.

289 Broennimann O., Treier UA., Müller-Schärer H., Thuiller W., Peterson AT., Guisan A. 2007. 290 Evidence of climatic niche shift during biological invasion. Ecology Letters 10:701-709. DOI: 291 10.1111/j.1461-0248.2007.01060.x.

292 Cannatella DC., De Sa RO. 1993. Xenopus laevis as a model organism. Systematic Biology 293 42:426-507. DOI: 10.1093/sysbio/42.4.476.

294 Caut S., Angulo E., Courchamp F. 2008. Dietary shift of an invasive predator: rats, seabirds and 295 sea turtles. Journal of Applied Ecology 45:428-437. DOI: 10.1111/j.1365-2664.2007.01438.x.

296 Chase JM., Leibold MA. 2003. Ecological niches: linking classical and contemporary 297 approaches. Chicago: The University of Chicago Press. DOI: 10.1007/s13398-014-0173-7.2.

298 Colwell RK., Futuyma DJ. 1971. On the measurement of niche breadth and overlap. Ecology 299 52:567-576. DOI: 10.2307/1934144. 
300 Comte L., Cucherousset J., Olden JD. 2016. Global test of Eltonian niche conservatism of

301 nonnative freshwater fish species between their native and introduced ranges. Ecography 39:1-9.

302 DOI: $10.1111 /$ ecog.02007.

303 Courant J., Thirion J., Guillon M., Grillet P., Grosselet O. 2014. Le régime alimentaire de 304 Xenopus laevis (Daudin, 1802) (Anura: Pipidae) introduit en France. Bulletin de la Société 305 Herpétologique de France 150:1-7.

306 Dalpadado P., Mowbray F. 2013. Comparative analysis of feeding ecology of capelin from two 307 shelf ecosystems, off Newfoundland and in the Barents Sea. Progress in Oceanography 114:97308 105. DOI: 10.1016/j.pocean.2013.05.007.

309 Faraone FP., Lillo F., Giacalone G., Lo Valvo M. 2008. The large invasive population of 310 Xenopus laevis in Sicily, Italy. Amphibia-Reptilia 29:405-412. DOI: $311 \quad 10.1163 / 156853808785112075$.

312 Gales RP. 1982. Age- and sex-related differences in diet selection by Rattus rattus on Stewart

313 Island, New Zealand. New Zealand Journal of Zoology 9:463-466. DOI:

$314 \quad 10.1080 / 03014223.1982 .10423878$.

315 Gkenas C., Magalhães MF., Cucherousset J., Domingos I., Ribeiro F. 2016. Long term patterns 316 in the late summer trophic niche of the invasive pumpkinseed sunfish Lepomis gibbosus.

317 Knowledge and Management of Aquatic Ecosystems 417:0-5. DOI: 10.1051/kmae/2016006. 
318 Göçmen B., Cicek K., Yildiz MZ., Atatur MK., Dincaslan YE., Mebert K. 2011. A preliminary

319 study on the feeding biology of the dice snake, Natrix tessellata, in Turkey. Mertensiella $320 \quad 18: 365-369$.

321 Guisan A., Tingley R., Baumgartner JB., Naujokaitis-Lewis I., Sutcliffe PR., Tulloch AIT., 322 Regan TJ., Brotons L., Mcdonald-Madden E., Mantyka-Pringle C., Martin TG., Rhodes JR., 323 Maggini R., Setterfield SA., Elith J., Schwartz MW., Wintle BA., Broennimann O., Austin M., 324 Ferrier S., Kearney MR., Possingham HP., Buckley YM. 2013. Predicting species distributions 325 for conservation decisions. Ecology Letters 16:1424-1435. DOI: 10.1111/ele.12189.

326 Ihlow F., Courant J., Secondi J., Herrel A., Rebelo R., Measey GJ., Lillo F., De Villiers FA., 327 Vogt S., De Busschere C., Backeljau T., Rödder D. 2016. Impacts of climate change on the 328 global invasion potential of the African clawed frog Xenopus laevis. PLoS ONE 11. DOI: 329 10.1371/journal.pone.0154869.

330 Lechowicz MJ. 1982. The sampling characteristics of electivity indices. Oecologia 52:22-30. 331 DOI: 10.1007/BF00349007.

332 Lobos G., Measey GJ. 2002. Invasive populations of Xenopus laevis (Daudin) in Chile. 333 Herpetological Journal 12:163-168.

334 Lobos G., Jaksic FM. 2005. The ongoing invasion of African clawed frogs (Xenopus laevis) in 335 Chile: Causes of concern. Biodiversity and Conservation 14:429-439.

336 Lodge DM. 1993. Biological invasions: lessons for ecology. Trends in Ecology \& Evolution $337 \quad 8: 133-136$. 
338 Luiselli LM., Capizzi D., Filippi E., Anibaldi C., Rugiero L., Capula M. 2007. Comparative diets

339 of three populations of an aquatic snake (Natrix tessellata, Colubridae) from mediterranean

340 streams with different hydric regimes. Copeia 2007:426-435. DOI: 10.1643/0045-

$3418511(2007) 7[426: C D O T P O] 2.0 . C O ; 2$.

342 McCoid MJ., Fritts TH. 1980. Notes on the diet of a feral population of Xenopus laevis (Pipidae)

343 in California. The SouthWestern Naturalist 25:272-275. DOI: 10.2307/3671256.

344 Measey GJ. 1998a. Diet of feral Xenopus laevis (Daudin) in South Wales, U.K. Journal of 345 Zoology 246:287-298.

346 Measey GJ. 1998b. Terrestrial prey capture in Xenopus laevis. Copeia 3:787-791.

347 Measey GJ. 2001. Growth and ageing of feral Xenopus laevis (Daudin) in South Wales, U.K. 348 Journal of Zoology 254:547-555.

349 Measey GJ., Rödder D., Green SL., Kobayashi R., Lillo F., Lobos G., Rebelo R., Thirion J-M.

350 2012. Ongoing invasions of the African clawed frog, Xenopus laevis: a global review. Biological

351 Invasions 14:2255-2270. DOI: 10.1007/s10530-012-0227-8.

352 Measey GJ., Vimercati G., de Villiers FA., Mokhatla MM., Davies SJ., Edwards S., Altwegg R. 353 2015. Frog eat frog: exploring variables influencing anurophagy. PeerJ 3:e1204. DOI: 354 10.7717/peerj.1204.

355 Measey GJ., Vimercati G., de Villiers FA., Mokhatla M., Davies SJ., Thorp CJ., Rebelo A., 356 Kumschick S. 2016. A global assessment of alien amphibian impacts in a formal framework. 357 Diversity and Distributions:1-12. DOI: 10.1017/CBO9781107415324.004. 
358 Mukherjee A., Williams DA., Wheeler GS., Cuda JP., Pal S., Overholt WA. 2012. Brazilian

359 peppertree (Schinus terebinthifolius) in Florida and South America: Evidence of a possible niche

360 shift driven by hybridization. Biological Invasions 14:1415-1430. DOI: 10.1007/s10530-011-

$361 \quad 0168-7$.

362 Rehage JS., Barnett BK., Sih A. 2005. Foraging behaviour and invasiveness: Do invasive

363 Gambusia exhibit higher feeding rates and broader diets than their noninvasive relatives?

364 Ecology of Freshwater Fish 14:352-360. DOI: 10.1111/j.1600-0633.2005.00109.x.

365 Ricciardi A., Rasmussen JB. 1998. Predicting the identity and impact of future biological

366 invaders: a priority for aquatic resource management. Canadian Journal of Fisheries and

367 Aquatic Sciences 55:1759-1765. DOI: 10.1890/02-0571.

368 Rödder D., Ihlow F., Courant J., Secondi J., Herrel A., Rebelo R., Measey GJ., Lillo F., de

369 Villiers FA., De Busschere C., Backeljau T. (press) Global realized niche divergence in the

370 African-clawed Frog Xenopus laevis. Ecology and Evolution.

371 Rutz C., Whittingham MJ., Newton I. 2006. Age-dependent diet choice in an avian top predator.

372 Proceedings of the Royal Society B: Biological Sciences 273:579-586. DOI:

$37310.1098 /$ rspb.2005.3353.

374 Schafer LN., Platell ME., Valesini FJ., Potter IC. 2002. Comparisons between the influence of

375 habitat type, season and body size on the dietary compositions of fish species in nearshore

376 marine waters. Journal of Experimental Marine Biology and Ecology 278:67-92. DOI:

377 10.1016/S0022-0981(02)00337-4. 
378 Schoonbee HJ., Prinsloo JF., Nxiweni JG. 1992. Observations on the feeding habits of larvae,

379 juvenile and adult stages of the African clawed frog, Xenopus laevis, in impoundments in

380 Transkei. Water SA 18:227-236.

381 Schramm M. 1987. Control of Xenopus laevis (Amphibia: Pipidae) in fish ponds with

382 observations on its threat to fish fry and fingerlings. Water SA 13:53-56.

383 Shannon CE., Weaver W. 1964. The mathematical theory of communication. In: University of

384 Illinois Press, 3-28.

385 Slatyer RA., Hirst M., Sexton JP. 2013. Niche breadth predicts geographical range size: A 386 general ecological pattern. Ecology Letters 16:1104-1114. DOI: 10.1111/ele.12140.

387 Soberón J. 2007. Grinnellian and Eltonian niches and geographic distributions of species. 388 Ecology Letters 10:1115-1123.

389 Stiels D., Gaißer B., Schidelko K., Engler JO., Rödder D. 2015. Niche shift in four non-native 390 estrildid finches and implications for species distribution models. Ibis 157:75-90. DOI: 391 10.1111/ibi.12194.

392 Tillberg C V., Holway DA., Lebrun EG., Suarez A V. 2007. Trophic ecology of invasive 393 Argentine ants in their native and introduced ranges. Proceedings of the National Academy of 394 Sciences of the United States of America 104:20856-20861. DOI: 10.1073/pnas.0706903105.

395 Tinsley RC., Stott LC., Viney ME., Mable BK., Tinsley MC. 2015. Extinction of an introduced 396 warm-climate alien species, Xenopus laevis, by extreme weather events. Biological Invasions 397 17:3183-3195. DOI: 10.1007/s10530-015-0944-x. 
398 Van Ngo B., Lee YF., Ngo CD. 2014. Variation in dietary composition of granular spiny frogs

399 (Quasipaa verrucospinosa) in central Vietnam. Herpetological Journal 24:245-253.

400 Vanderploeg HA., Scavia D. 1979. Calculation and use of selectivity coefficients of feeding:

401 Zooplankton grazing. Ecological Modelling 7:135-149. DOI: 10.1016/0304-3800(79)90004-8.

402 Vazquez DP. 2006. Exploring the relationship between niche breadth and invasion success. In:

403 Cadotte MW, McMahon SM, Fukami T, eds. Conceptual ecology and invasions biology.

404 Dordrecht: Springer International Publishing, 317-332.

405 Vogt S., De Villiers FA., Ihlow F., Rödder D., Measey GJ. (press.) Competition and feeding 406 ecology in two sympatric Xenopus species (Anura: Pipidae). PeerJ.

407 Wiens JJ., Graham CH. 2005. Niche conservatism: Integrating evolution, ecology, and 408 conservation biology. Annual Review of Ecology, Evolution, and Systematics 36:519-539. DOI:

409 10.1146/annurev.ecolsys.36.102803.095431.

410 Wu Z-J., Li Y-M., Wang Y-P. 2007. A comparison of stomach flush and stomach dissection in 411 diet analysis of four frog species. Acta Zoologica Sinica 53:364-372. 


\section{Figure 1 (on next page)}

Two first principal components of the PCA representing the populations according to their diet. 


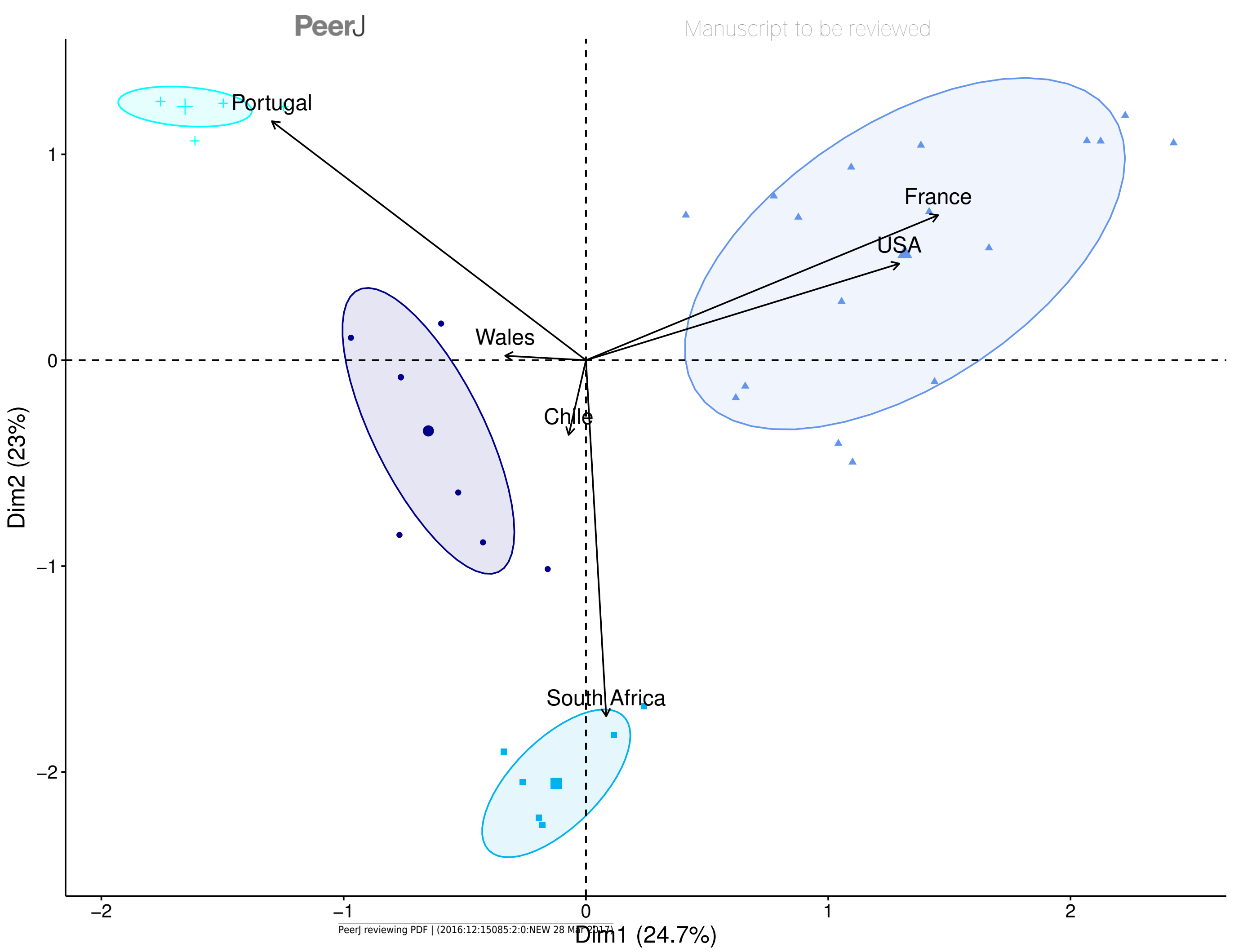


Figure 2 (on next page)

Occurrence of the main ecological traits among the five populations.

Terrestrial prey (black), benthic prey (dark blue), nektonic items (sky blue) and planktonic prey (cyan). 


\section{PeerJ}

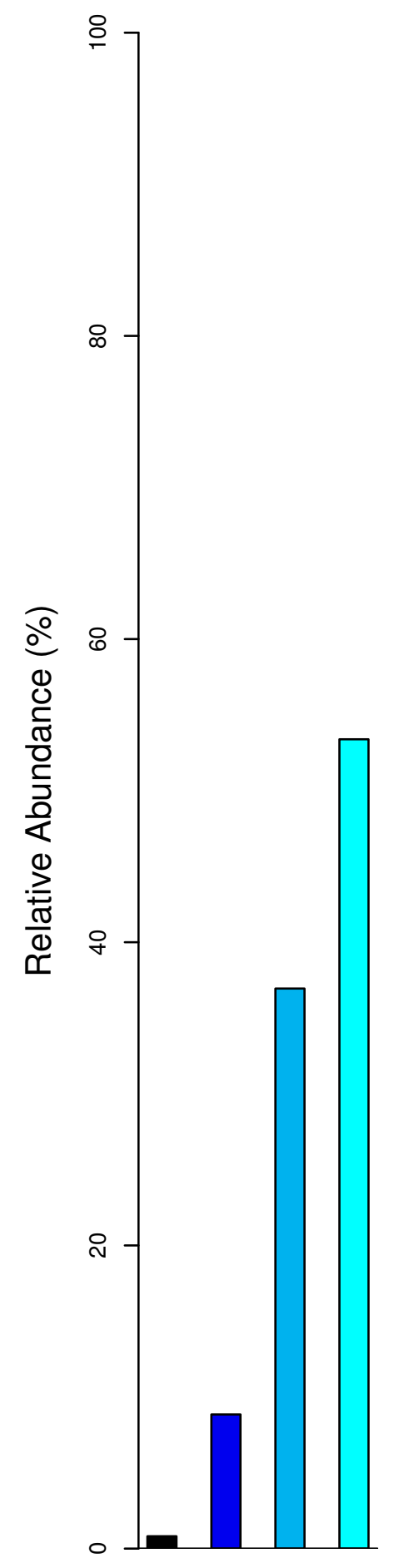

South Africa
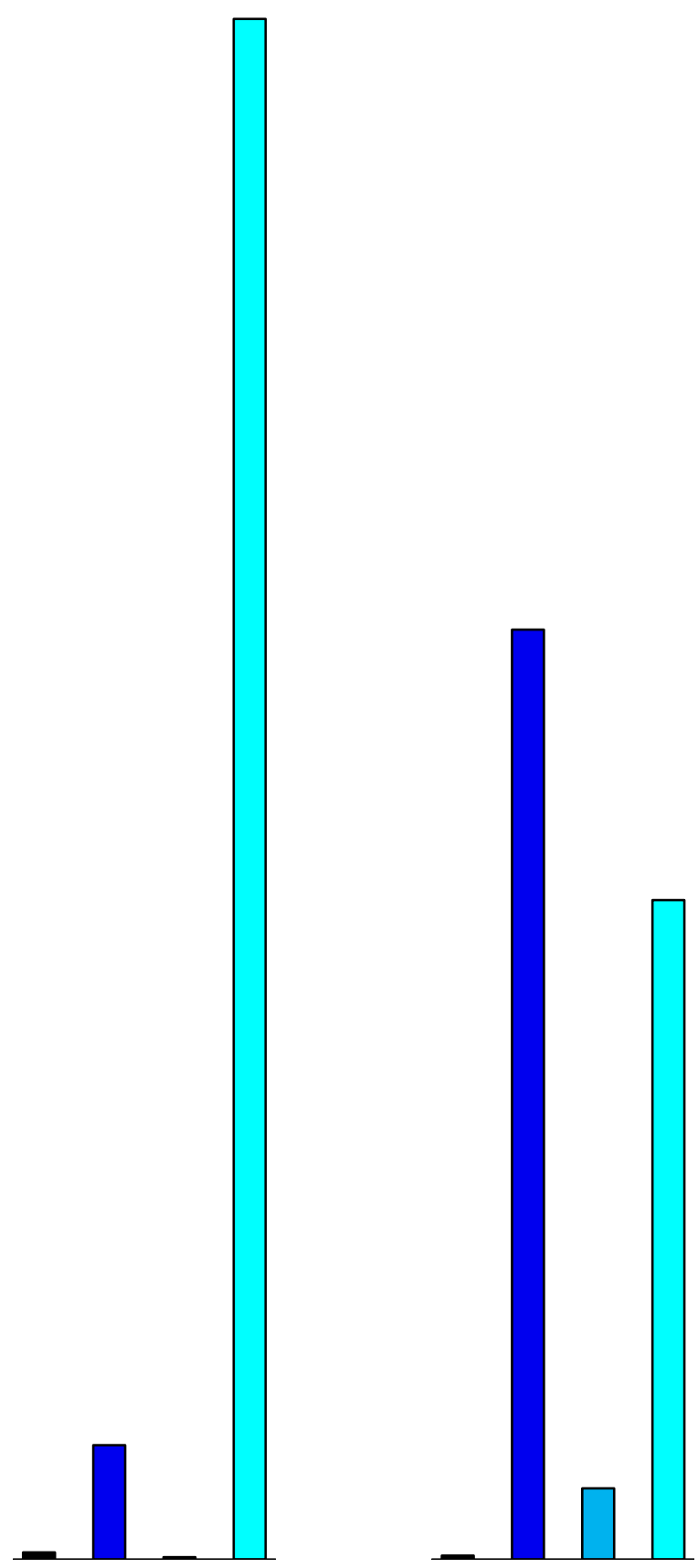

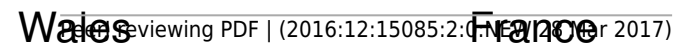

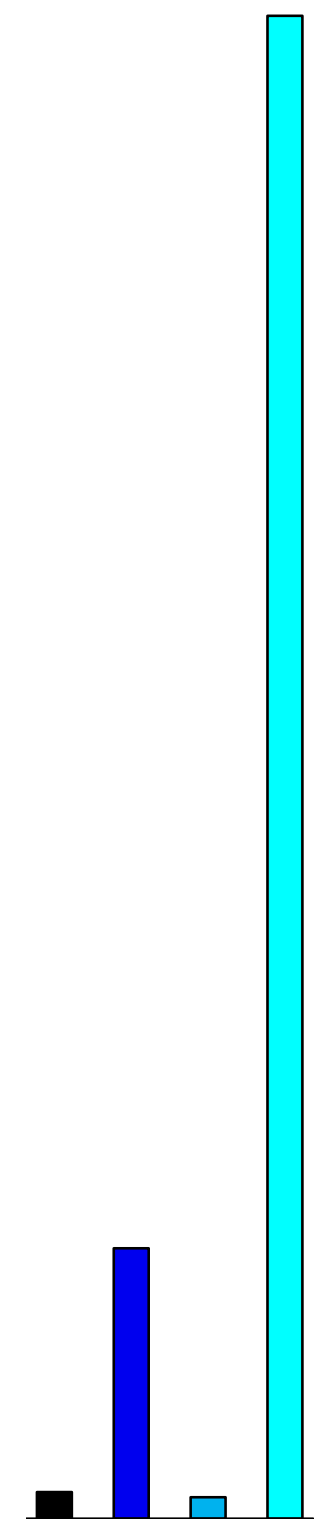

Chile

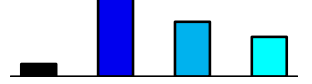

Portugal

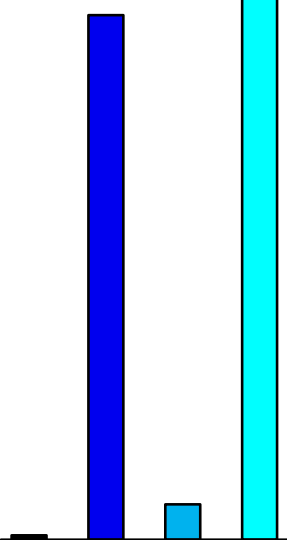

USA 


\section{Figure 3 (on next page)}

Niche breadth calculated for diet data in native and colonized ranges of Xenopus laevis

Calculated with the Evenness J' (A) and relationship between J' and the number of sites $N_{S}$ used in localities (B). 


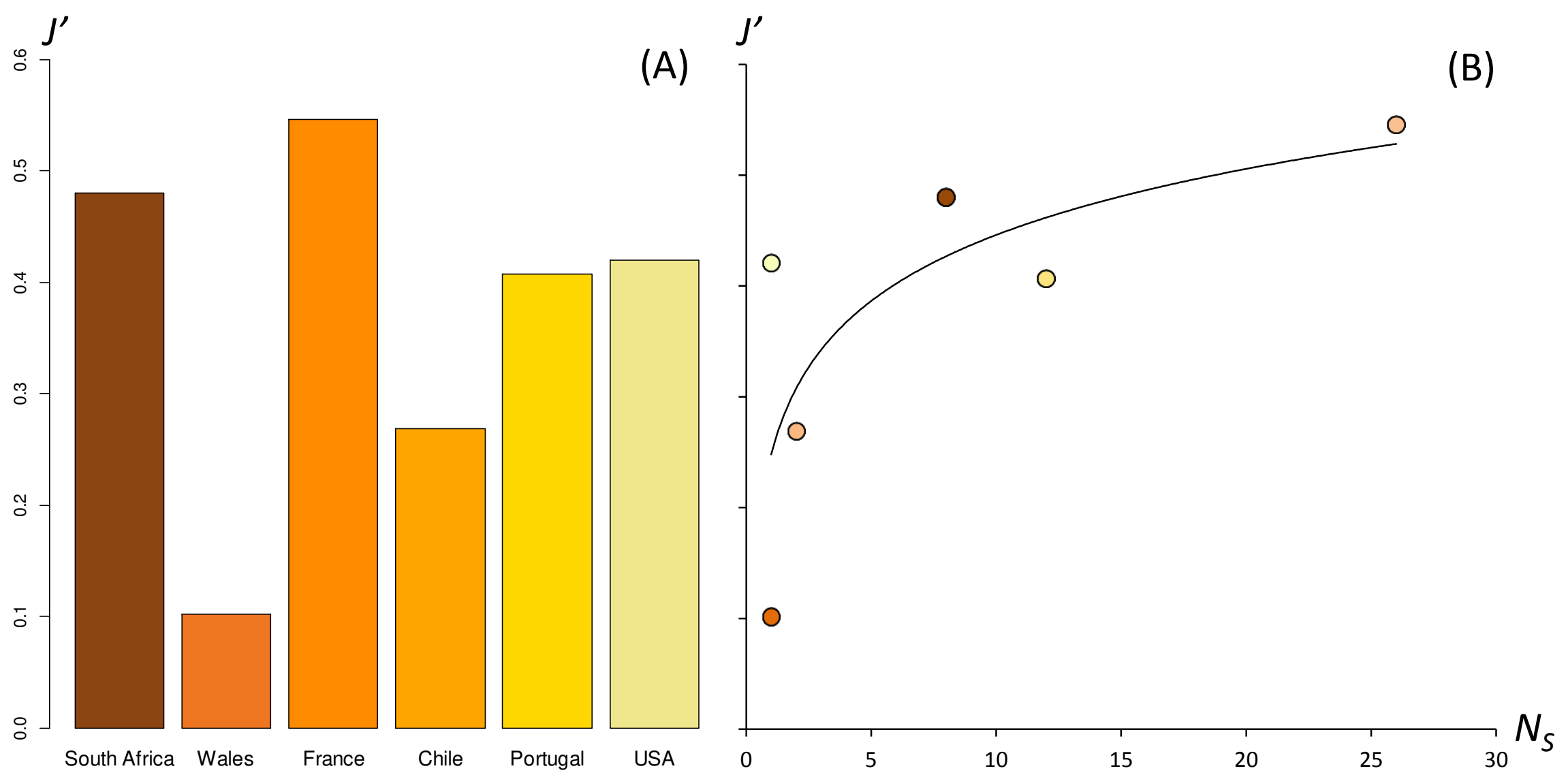


Figure 4 (on next page)

Electivity index for each aquatic prey category consumed in South Africa (brown), Wales (dark-orange) and France (light-orange) 
PeerJ

Electivity

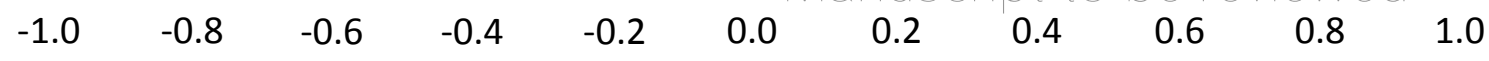

Zooplankton

Gastropoda

Acari

Amphipoda

Coleoptera

Diptera

Heteroptera

Zygoptera

Anisoptera

Ephemeroptera

Trichoptera

Amphibia

Oligochaeta 


\section{Table $\mathbf{1}$ (on next page)}

Characteristics of the methods used to capture and describe the diet of Xenopus laevis.

*The population introduced in Wales went extinct twenty years after the data collection used in our study (Tinsley et al., 2015). ** Geographical coordinates (WGS 84), northwestern (NW) and southeastern corners (SE), of the minimum rectangle encompassing all sampled sites for $N_{s}>1$. 


\begin{tabular}{|c|c|c|c|c|c|c|}
\hline & South Africa & Wales & France & Chile & Portugal & USA \\
\hline \multicolumn{7}{|l|}{ Population status } \\
\hline & Native & Extinct* & Invasive & Invasive & Invasive & Invasive \\
\hline \multicolumn{7}{|l|}{ Period of capture } \\
\hline & From 06/2014 & From 05/1995 & From 05/2014 & $01 / 1998$ & From 06/2014 & $1975-1976$ \\
\hline & To-09/2014 & To 08/1996 & To $10 / 2014$ & $03 / 2001$ & To $08 / 2014$ & \\
\hline \multicolumn{7}{|l|}{ Geographical coordinates } \\
\hline \multirow{2}{*}{ Latitude/Longitude $\mathrm{NW}^{* *}$} & & & & & & \\
\hline & E $18^{\circ} 25^{\prime} 35^{\prime \prime}$ & $W 3^{\circ} 33^{\prime} 11^{\prime \prime}$ & W 0 $33^{\prime} 56^{\prime \prime}$ & $W 70^{\circ} 54^{\prime}$ & W 9 $17^{\prime} 27^{\prime \prime}$ & \& Fritts, 1980 \\
\hline \multirow[t]{2}{*}{ Latitude/Longitude SE** } & & NA & & & & \\
\hline & E $19^{\circ} 04^{\prime} 29^{\prime \prime}$ & & W $0^{\circ} 31^{\prime} 11^{\prime \prime}$ & W $70^{\circ} 39^{\prime}$ & W 9 $16^{\prime} 25^{\prime \prime}$ & \& Fritts, 1980 \\
\hline \multicolumn{7}{|l|}{ Sampling design } \\
\hline Method & Trap & Trap & Trap & Trap & Electrofishing & NA \\
\hline Capture occasion/site & From 1 to 4 & 29 & 3 & 1 & From 1 to 4 & 1 \\
\hline Number of sites & 8 & 1 & 26 & 2 & 12 & 1 \\
\hline Number of individuals & 164 & 375 & 438 & 48 & 352 & 81 \\
\hline Prey Availability & Yes & Yes & Yes & No & No & No \\
\hline Habitat Type & Ponds & Pond & Ponds & Ponds & Streams & Streams \\
\hline
\end{tabular}

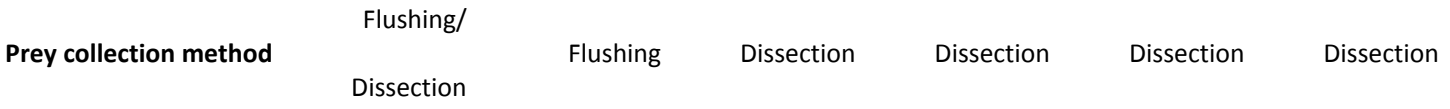

\begin{tabular}{|c|c|c|c|c|c|c|}
\hline \multicolumn{7}{|l|}{ Published data } \\
\hline Prey frequency in stomachs & Yes & Yes & No & Yes & No & Yes \\
\hline Niche breadth & Yes & No & No & No & No & No \\
\hline Electivity & Yes & Yes & No & No & No & No \\
\hline \multicolumn{7}{|l|}{ Individual data } \\
\hline & Yes & No & Yes & Yes & Yes & No \\
\hline
\end{tabular}




\section{Table 2 (on next page)}

Relative abundance (in \%) of the prey items identified in the native and colonized ranges of Xenopus laevis.

When prey items are observed in very low quantities $(\mathrm{N}<3)$, they are noted as $<0.01 \%$ in the table.The main prey categories of each populations are underlined. Below the name of each ecological category, we mention the mean and the standard deviation of the relative abundance of items found in stomach contents. 


\begin{tabular}{|c|c|c|c|c|c|c|c|c|}
\hline & Cat & & South Africa & Wales & France & Chile & Portugal & USA \\
\hline \multirow[t]{2}{*}{ Aquatic invertebrates } & & & 65.99 & 99.15 & 80.68 & 98.54 & 96.56 & 98.13 \\
\hline & 1 & Zooplankton & $\underline{51.87}$ & $\underline{92.55}$ & $\underline{39.62}$ & $\underline{82.51}$ & 2.28 & $\underline{68.89}$ \\
\hline \multicolumn{2}{|l|}{ Benthos } & & 8.86 & 6.45 & 37.08 & 14.85 & 93.90 & 27.41 \\
\hline \multicolumn{9}{|l|}{$34.80 \% \pm 34.17 \%$} \\
\hline & 2 & Annelids & 0.03 & 0.00 & 0.02 & 0.00 & 0.05 & 0.00 \\
\hline & 3 & Turbellaria & 0.00 & $<0.01$ & 0.00 & 0.00 & 0.00 & 0.00 \\
\hline & 4 & Gastropoda & 0.00 & 0.00 & 9.82 & 10.64 & 15.05 & 7.99 \\
\hline & 5 & Bivalvia & 0.00 & 0.24 & 0.44 & 0.00 & 0.05 & 0.00 \\
\hline & 6 & Acari & 4.63 & 0.00 & 0.00 & 0.00 & 0.05 & 0.00 \\
\hline & 8 & Amphipoda & 1.83 & 0.02 & 3.09 & 0.00 & 0.05 & 4.21 \\
\hline & 9 & Isopoda & 0.00 & 0.00 & 0.00 & 0.00 & 2.62 & 0.05 \\
\hline & 10 & Decapoda & 0.0 & 0.00 & 0.00 & 0.00 & 0.06 & 0.00 \\
\hline & 11 & Diptera (larvae) & 1.78 & $\underline{6.14}$ & $\underline{20.90}$ & 4.21 & $\underline{15.24}$ & $\underline{9.91}$ \\
\hline & 12 & Ephemeroptera (larvae) & 0.00 & 0.05 & 2.79 & 0.00 & 58.02 & 0.98 \\
\hline & 13 & Trichoptera (larvae) & 0.59 & 0.00 & 0.02 & 0.00 & 2.71 & 4.27 \\
\hline \multicolumn{2}{|l|}{ Nekton } & & 5.26 & 0.14 & 4.00 & 1.19 & 0.50 & 1.83 \\
\hline \multicolumn{9}{|l|}{$7.74 \% \pm 13.87 \%$} \\
\hline & 14 & Coleoptera (larvae) & 1.97 & 0.03 & 0.02 & 0.00 & 0.06 & 0.27 \\
\hline & 15 & Coleoptera (adult) & 0.67 & 0.09 & 1.74 & 0.44 & 0.38 & 0.34 \\
\hline & 16 & Heteroptera & 1.09 & 0.02 & 1.12 & 0.18 & 0.01 & 0.16 \\
\hline & 17 & Zygoptera (larvae) & 0.79 & 0.00 & 0.38 & 0.44 & 0.00 & 0.53 \\
\hline & 18 & Anisoptera (larvae) & 0.74 & 0.00 & 0.74 & 0.13 & 0.05 & 0.53 \\
\hline \multicolumn{3}{|l|}{ Terrestrial invertebrates } & 0.86 & 0.43 & 0.23 & 1.46 & 0.70 & 0.24 \\
\hline \multicolumn{9}{|l|}{$0.64 \% \pm 0.46 \%$} \\
\hline & 19 & Arachnida & 0.46 & 0.01 & 0.00 & 1.21 & 0.05 & 0.11 \\
\hline & 20 & Isopoda & 0.00 & 0.05 & 0.00 & 0.03 & 0.04 & 0.00 \\
\hline & 21 & Chilopoda & 0.00 & 0.00 & 0.00 & 0.00 & 0.01 & 0.00 \\
\hline & 22 & Diplopoda & 0.00 & 0.00 & 0.00 & 0.00 & 0.01 & 0.00 \\
\hline & 23 & Diptera & 0.09 & 0.06 & 0.00 & 0.00 & 0.04 & 0.08 \\
\hline & 24 & Neuroptera & 0.04 & 0.00 & 0.00 & 0.00 & 0.00 & 0.00 \\
\hline & 25 & Hymenoptera & 0.27 & 0.00 & 0.00 & 0.05 & 0.16 & 0.00 \\
\hline & 26 & Coleoptera & 0.00 & 0.01 & 0.05 & 0.00 & 0.00 & 0.05 \\
\hline & 27 & Lepidoptera (larvae) & 0.00 & $<0.01$ & 0.00 & 0.00 & 0.00 & 0.00 \\
\hline & 28 & Lepidoptera (adult) & 0.00 & 0.00 & 0.00 & 0.15 & 0.00 & 0.00 \\
\hline & 29 & Dermaptera & 0.00 & 0.01 & 0.00 & 0.03 & 0.00 & 0.00 \\
\hline & 30 & Heteroptera & 0.00 & 0.00 & 0.02 & 0.00 & 0.10 & 0.00 \\
\hline & 31 & Annelids & 0.00 & 0.02 & 0.09 & 0.00 & 0.02 & 0.00 \\
\hline & 32 & Orthoptera & 0.00 & 0.00 & 0.08 & 0.00 & 0.00 & 0.00 \\
\hline & 33 & Aphids & 0.00 & 0.27 & 0.00 & 0.00 & 0.00 & 0.00 \\
\hline & 34 & Trichoptera & 0.00 & 0.00 & 0.00 & 0.00 & 0.02 & 0.00 \\
\hline & 35 & Ephemeroptera & 0.00 & 0.00 & 0.00 & 0.00 & 0.24 & 0.00 \\
\hline \multicolumn{2}{|l|}{ Vertebrates } & & 33.13 & 0.41 & 19.09 & 0.00 & 2.74 & 1.63 \\
\hline \multicolumn{9}{|l|}{$9.45 \% \pm 13.54 \%$} \\
\hline & 36 & Fish (adult) & 0.00 & 0.00 & 0.11 & 0.00 & 0.02 & 0.08 \\
\hline & 37 & Fish (egg) & 0.00 & 0.00 & 0.00 & 0.00 & 0.82 & 0.00 \\
\hline & 38 & Amphibia (adult) & 0.14 & 0.00 & 0.02 & 0.00 & 0.00 & 0.00 \\
\hline & 3 & Amphibia (larvae) & 3.37 & 0.00 & 0.00 & 0.00 & 0.00 & 0.00 \\
\hline & 39 & Amphibia (egg) & $\underline{27.62}$ & 0.00 & 0.08 & 0.00 & 1.65 & 0.00 \\
\hline & 40 & $X$. laevis (larvae) & 0.04 & 0.00 & 0.08 & 0.00 & 0.01 & 0.03 \\
\hline & 41 & X. laevis (egg) & 0.00 & 0.41 & $\underline{18.81}$ & 0.00 & 0.00 & 1.52 \\
\hline & 42 & Amphibia (rest) & 1.98 & 0.01 & 0.00 & 0.00 & 0.22 & 0.00 \\
\hline & 43 & Bird (feather) & 0.00 & $<0.01$ & 0.00 & 0.00 & $<0.01$ & 0.00 \\
\hline & 44 & Mammals & 0.00 & $<0.01$ & 0.00 & 0.00 & 0.00 & 0.00 \\
\hline
\end{tabular}


